\title{
Ponto de murcha permanente fisiológico e potencial osmótico de feijão caupi cultivado em solos salinizados
}

\author{
José B. M. Coelho ${ }^{1}$, Maria de F. C. Barros ${ }^{2}$, Egídio Bezerra Neto ${ }^{3}$ \& Edivan R. de Souza ${ }^{4}$
}

\author{
${ }^{1}$ Departamento de Química/UFRPE. Recife, PE. E-mail: josebenjamin@terra.com.br (Autor correspondente) \\ ${ }^{2}$ Departamento de Agronomia/UFRPE. E-mail: fatima@depa.ufrpe.br \\ ${ }^{3}$ Departamento de Química/UFRPE. E-mail: egidiobn@yahoo.com.br \\ ${ }^{4}$ Departamento de Agronomia/UFRPE. E-mail: edivanrs@hotmail.com
}

\section{Palavras-chave:}

Vigna unguiculata

estresse salino

umidade foliar

\begin{abstract}
R E S U M O
Com o objetivo de avaliar o ponto de murcha permanente fisiológico, a umidade foliar e o potencial osmótico no feijoeiro caupi, sob duas condições de estresses (salino e salino + hídrico), foram conduzidos dois experimentos em casa de vegetação na Universidade Federal Rural de Pernambuco (Recife, PE, Brasil). O delineamento experimental adotado foi o inteiramente casualizado, em arranjo fatorial $2 \times 4$, sendo duas classes texturais de solos (francoarenoso e franco-argiloso) e quatro níveis de salinidade do solo, equivalentes às condutividades elétricas do extrato de saturação do solo 4, 8 e $12 \mathrm{dS} \mathrm{m}^{-1}$, mais testemunha, com cinco repetições. A cultura teste utilizada foi o feijoeiro caupi [Vigna unguiculata L. (Walp.)], cultivar Pele de Moça. O ponto de murcha permanente do feijoeiro caupi é menor quando determinado pelo método fisiológico do que o determinado na câmara de pressão de Richards; o incremento da salinidade do solo $\left(\mathrm{CE}_{\mathrm{es}}\right)$ até $12 \mathrm{dS} \mathrm{m}^{-1}$ não influencia a umidade foliar, independente da textura do solo; e o potencial osmótico foliar do feijoeiro caupi diminui com o aumento da salinidade do solo e pode ser usado como variável importante em ambientes salinizados.
\end{abstract}

Key words: Vigna unguiculata salt stress leaf moisture

\section{Physiological permanent wilting point and osmotic potential of cowpea grown in saline soils}

\begin{abstract}
A B S T R A C T
In order to evaluate the physiological wilting point, the moisture content and leaf osmotic potential in cowpea, two experiments were carried out in a greenhouse of the Federal Rural University of Pernambuco (Recife, PE, Brazil). Two stress conditions were evaluated: salinity and salinity + water stress. The experimental design was completely randomized, in factorial arrangement of $2 \times 4$, composed of two classes of soil texture and four levels of soil salinity (control, 4, 8 and $12 \mathrm{dS} \mathrm{m}^{-1}$ ), with five replications. The species cowpea [Vigna unguiculata $\mathrm{L}$. (Walp.)], cultivar Pele de Moça was used as test crop. It was concluded that the permanent wilting point of cowpea is smaller when determined by the physiological method than by Richards chamber method; the increase in soil salinity $\left(\mathrm{CE}_{\mathrm{es}}\right)$ up to $12 \mathrm{dS} \mathrm{m}^{-1}$ does not influence the leaf moisture content, regardless of soil texture; and the leaf osmotic potential of cowpea decreases with the increasing soil salinity, which can be used as an important variable in saline environments.
\end{abstract}

\section{INTRODUÇÃo}

A quantificação da água no solo, juntamente com a caracterização do seu estado energético, é fundamental para otimizar o manejo da água no sistema solo-planta. No manejo da irrigação em áreas salinizadas, quando não é considerado o componente osmótico para o cálculo do potencial total da água no solo, pode ocorrer o murchamento precoce de plantas ou a aplicação de água em excesso, com impactos negativos na produção e no rendimento de culturas. Nessas condições é aconselhável adequar a quantidade de água aplicada e a frequência de rega visando ao uso mais eficiente da água. Para a determinação do ponto de murcha permanente o método padrão é o fisiológico, empregado por Briggs \& Shantz (1912) mas é trabalhoso e exige muito tempo, o que torna prática usual estimar o ponto de murcha permanente equivalente à água retida no solo na tensão de 1,5 $\mathrm{MPa}$. Entretanto, alguns autores relatam valores de ponto de murcha permanente diferentes dos obtidos pelo método da câmara de pressão de Richards (Klute, 1986) em relação ao método fisiológico alegando a influência da espécie na definição da tensão de murchamento permanente (Klein et al., 2006; Alves et al., 2010).

Solos salinos podem limitar a produção de culturas em muitas áreas do mundo (Patel et al., 2010). A salinização do solo reduz a capacidade das plantas de absorver água com um conjunto de alterações metabólicas, semelhantes às provocadas pelo estresse hídrico (Munns, 2002). Na literatura são raros os trabalhos que relacionam o ponto de 
murcha permanente determinado pelo método fisiológico em ambientes salinos.

A relevância do estudo do potencial osmótico das plantas se deve ao fato desta variável ser considerada a principal componente do potencial hídrico em ambientes salinos. BenGal et al. (2009) e Souza et al. (2012) relatam que a salinidade de águas e solos, tem sido frequentemente relacionada com a condutividade elétrica, por ser um método de determinação prático e rápido porém a apresentação e a interpretação de respostas da planta à salinidade, em termos de potencial osmótico, é mais adequada haja vista que possibilita diferenciar entre os efeitos tóxicos e osmóticos da salinidade.

O feijão caupi, também conhecido como feijão de corda, feijão vigna e feijão macassar, é amplamente cultivado em regiões áridas e semiáridas constituindo-se em um dos principais componentes da dieta alimentar dessas populações (Lima et al., 2007). Conforme Ayers \& Westcot, (1999), a referida cultura tolera irrigação com água salina com condutividade elétrica de até $3,3 \mathrm{dS} \mathrm{m}^{-1}$ e condutividade elétrica do extrato de saturação do solo de até $4,9 \mathrm{dS} \mathrm{m}^{-1}$ sendo considerada uma espécie moderadamente tolerante à salinidade (Ayers \& Westcot, 1999). Sabe-se, no entanto, que esta afirmação depende do tipo de solo e da fração de lixiviação empregada.

Objetivou-se avaliar o efeito dos estresses salino e salino + hídrico sobre o ponto de murcha permanente fisiológico, umidade foliar e potencial osmótico do feijoeiro caupi.

\section{Material e Métodos}

Dois experimentos foram conduzidos simultaneamente, em casa de vegetação pertencente à Universidade Federal Rural de Pernambuco, localizada em Recife, PE, latitude de $08^{\circ} 00^{\prime} 57^{\prime \prime} \mathrm{S}$, longitude de $34^{\circ} 57^{\prime} 02^{\prime \prime} \mathrm{W}$. A pesquisa foi realizada nos meses de setembro e outubro de 2011. No primeiro experimento estudou-se o efeito do estresse salino sobre o potencial osmótico foliar do feijoeiro caupi e no segundo avaliou-se o efeito do estresse salino seguido da suspensão da irrigação sobre o ponto de murcha permanente fisiológico e potencial osmótico foliar do feijoeiro caupi. Durante a condução dos experimentos a temperatura média e a umidade relativa do ar foram, dentro da casa de vegetação, de $28,5^{\circ} \mathrm{C}$ e $70,8 \%$, respectivamente.

Os experimentos foram realizados usando-se o delineamento experimental inteiramente casualizado, constando de um arranjo fatorial $2 \times 4$, sendo duas classes texturais de solos (franco-arenoso e franco-argiloso) com quatro níveis de salinidade do solo equivalentes às condutividades elétricas do extrato de saturação $\left(\mathrm{CE}_{\mathrm{es}}\right)$ de 4,8 e $12 \mathrm{dS} \mathrm{m}^{-1}$, além das testemunhas (sem adição de sal) e 5 repetições totalizando 40 parcelas em cada experimento. A cultura-teste utilizada foi o feijão caupi [Vigna unguiculata L. (Walp.)] cultivar Pele de Moça.
Foram utilizados dois materiais de Neossolos Flúvicos, coletados nos municípios semiáridos de Ibimirim e Parnamirim, PE, com texturas franco-arenosa e franco-argilosa, respectivamente. A caracterização física dos solos foi realizada de acordo com a metodologia descrita pela EMBRAPA (1997) descrita na Tabela 1.

Antes da condução dos experimentos (testemunhas) a pasta saturada dos solos foi preparada de acordo com a metodologia descrita por Richards (1954) determinando-se, no extrato da pasta saturada, a condutividade elétrica e os cátions solúveis: sódio e potássio, por fotometria de chama e cálcio e magnésio, por espectrometria de absorção atômica (Tabela 2). Foram quantificados, com os teores de cálcio, magnésio e sódio, os valores da relação de adsorção de sódio (RAS) pela Eq. 1.

$$
\operatorname{RAS}=\frac{\mathrm{Na}}{\left[\frac{(\mathrm{Ca}+\mathrm{Mg})}{2}\right]^{1 / 2}}
$$

em que:

RAS - relação de adsorção de sódio

$\mathrm{Na}^{+}$- concentração de sódio, $\mathrm{mmol}_{\mathrm{c}} \mathrm{L}^{-1}$

$\mathrm{Ca}^{+2}$ - concentração de cálcio, $\mathrm{mmol}_{\mathrm{c}} \mathrm{L}^{-1}$

$\mathrm{Mg}^{+2}$ - concentração de magnésio, $\mathrm{mmol}_{\mathrm{c}} \mathrm{L}^{-1}$

Tabela 2. Caracterização química do extrato de saturação dos solos

\begin{tabular}{|c|c|c|c|c|c|c|}
\hline \multirow{2}{*}{$\begin{array}{c}\text { Classe } \\
\text { textural }\end{array}$} & \multirow{2}{*}{$\begin{array}{c}\text { CE } \\
\left(\mathrm{dS} \mathrm{m}^{-1}\right)\end{array}$} & \multicolumn{4}{|c|}{ Cátions solúveis (mmolc $\mathrm{L}^{-1}$ ) } & \multirow{2}{*}{$\begin{array}{c}\text { RAS } \\
\left(\mathrm{mmol} \mathrm{L}^{-1}\right)^{0,5}\end{array}$} \\
\hline & & $\mathrm{Ca}^{+2}$ & $\mathrm{Mg}^{+2}$ & $\mathrm{Na}^{+}$ & $\mathrm{K}^{+}$ & \\
\hline Fr. arenoso & 2,2 & 11,5 & 2,0 & 7,1 & 2,4 & 2,7 \\
\hline Fr. argiloso & 2,4 & 10,3 & 3,5 & 8,6 & 1,9 & 3,3 \\
\hline
\end{tabular}

Com o objetivo de estimar a quantidade de sais correspondentes aos tratamentos salinos, realizou-se um ensaio preliminar utilizando uma mistura de sais composta de $2 / 3 \mathrm{de} \mathrm{NaCl}$ e $1 / 3$ de $\mathrm{CaCl}_{2}$ (Coelho et al., 2013); em seguida, procedeu-se à incubação dos solos empregando-se as concentrações de zero a $5 \mathrm{~g}$ dessa mistura de sais por kg de solo, na forma de uma pasta saturada (Richards, 1954). Após a incubação dos solos pelo período de $24 \mathrm{~h}$, foram obtidos os extratos das pastas saturadas e se mediu a condutividade elétrica, o que proporcionou as seguintes equações: $y=6,787 x+2,634$ (solo franco-arenoso); $y=4,385 x$ $+2,526$ (solo franco-argiloso); em que $x$ é a concentração salina, em $\mathrm{g} \mathrm{kg}^{-1} \mathrm{e}$ y corresponde à condutividade elétrica do extrato saturado, $\mathrm{dS} \mathrm{m}^{-1}$.

As unidades experimentais foram constituídas de duas plantas contidas em vasos plásticos com capacidade de $3,2 \mathrm{dm}^{3}$, contendo um sistema de drenagem em sua base para permitir o fluxo do lixiviado. A irrigação da cultura foi atendida mediante a aplicação de volumes de água destilada, diariamente, para

Tabela 1. Caracterização física dos solos

\begin{tabular}{|c|c|c|c|c|c|c|c|}
\hline \multirow{2}{*}{$\begin{array}{c}\text { Classe } \\
\text { textural }\end{array}$} & \multicolumn{3}{|c|}{ Granulometria $\left(\mathrm{g} \mathrm{kg}^{-1}\right)$} & \multicolumn{2}{|c|}{ Densidade $\left(\mathrm{kg} \mathrm{dm}^{-3}\right)$} & \multicolumn{2}{|c|}{ Umidade $\left(\mathrm{g} \mathrm{g}^{-1}\right)$} \\
\hline & Areia & Silte & Argila & ds & $d p$ & $\left(^{(*)} \mathbf{C C}\right.$ & $\left.{ }^{(* \star}\right)$ PMP \\
\hline Fr. arenoso & 782 & 120 & 98 & 1,54 & 2,45 & 0,13 & 0,02 \\
\hline Fr. argiloso & 442 & 260 & 298 & 1,35 & 2,61 & 0,26 & 0,06 \\
\hline
\end{tabular}

${ }^{*}$ Capacidade de campo: solo franco-arenoso (-0,01 MPa); solo franco-argiloso (-0,033 MPa); ; ${ }^{*}$ Ponto de murcha permanente (-1,5 MPa); ds - Densidade do solo; dp - Densidade de partículas 
o solo de textura franco-arenosa e a cada dois dias para o solo de textura franco-argilosa, até que ocorresse o início da drenagem do lixiviado em cada vaso. Durante toda a condução dos experimentos os líquidos drenados foram reutilizados nas parcelas correspondentes visando à reposição dos sais.

No experimento cujos tratamentos foram submetidos apenas a estresse salino, a colheita das plantas ocorreu aos 28 dias após a semeadura, ocasião em que as plantas do tratamento testemunha apresentavam quatro folhas definitivas expandidas enquanto que no experimento com estresse salino seguido da suspenção da irrigação, a colheita das plantas foi realizada a partir do estabelecimento do ponto de murcha permanente fisiológico no tratamento testemunha. Para ambos os experimentos foram colhidas folhas do terço médio das plantas para realizar a medição do potencial osmótico e umidade foliar.

Ponto de murcha permanente fisiológico (PMPF) - Verificouse, em pré-testes realizados, que as plantas dos tratamentos mais salinos só atingem a umidade de murcha permanente após um prolongado período de tempo, o que ocasiona o amarelecimento e a queda de folhas, favorecendo a limitação na disponibilidade de biomassa foliar para a realização das diversas análises ante $o$ que se estabeleceu, como critério para a colheita das plantas do experimento submetido a estresse salino seguido de suspensão da irrigação, o momento em que as plantas do tratamento testemunha entravam em murcha permanente.

Visando à determinação do PMPF, foi utilizada a metodologia desenvolvida por Briggs \& Shantz (1912). O solo foi mantido em condições de umidade próxima à capacidade de campo, até a planta correspondente ao tratamento testemunha apresentar quatro folhas definitivas expandidas. Atingida esta condição, o umedecimento do solo foi suspenso e sua superfície coberta com papel alumínio deixando-se apenas dois orifícios para as passagens das hastes das plantas. Ao apresentar sintomas de murchamento incipiente, plantas foram transferidas para câmara úmida e escura, por períodos de $24 \mathrm{~h}$, sucessivas vezes para recuperar a turgescência de suas folhas. Ao restabelecer a turgescência, as plantas retornavam para a bancada da casa de vegetação. Este procedimento teve continuidade até as plantas atingirem a murcha máxima e irreversível. No momento em que foi estabelecido o ponto de murcha permanente no tratamento testemunha, as plantas deste e de todos os outros tratamentos foram colhidas. Imediatamente, foram coletadas também amostras de solo na profundidade de 5 a $15 \mathrm{~cm}$ com vista à determinação da umidade do solo no ponto de murcha permanente fisiológico (tratamento testemunha) e da umidade atual (demais tratamentos).

Umidade da folha - Utilizaram-se amostras de folhas tomando-se a massa do material em estado úmido e em seguida submetendo-as a secagem em estufa a $100{ }^{\circ} \mathrm{C}$, até as mesmas atingirem a massa constante (Bezerra Neto \& Barreto, 2011). A umidade foi determinada com base na relação entre a massa da água contida na folha e a massa da mesma em estado úmido, através da Eq. 2:

$$
\mathrm{U}=\frac{[(\mathrm{BMU}-\mathrm{BMS}) 100]}{\mathrm{BMU}}
$$

em que:

$$
\begin{aligned}
& \mathrm{U} \quad \text { - umidade da folha, dag } \mathrm{kg}^{-1} \\
& \text { BMU - biomassa úmida, } \mathrm{g} \\
& \text { BMS - biomassa seca em estufa, } \mathrm{g}
\end{aligned}
$$

Potencial osmótico da seiva foliar - Para a extração da seiva foliar do feijoeiro caupi, colocaram-se folhas dentro de um tubo de Eppendorf previamente perfurado na base, o qual funcionou como minifiltro. Com um bastão de vidro fez-se a prensagem do tecido foliar ocasionando a extração da seiva que foi coletada em outro tubo de Eppendorf; em seguida, o extrato foi centrifugado a $10.000 \mathrm{~g}$ durante $10 \mathrm{~min}$ a $4^{\circ} \mathrm{C}$. Uma alíquota de $10 \mu \mathrm{L}$ do sobrenadante foi utilizada para determinação da osmolalidade do tecido foliar do feijão através de um osmômetro de pressão de vapor, modelo Wescor 5520 . Os valores de potencial osmótico foram obtidos a partir da osmolalidade $\left(\mathrm{mmol} \mathrm{kg}^{-1}\right)$ da seiva do tecido foliar, mediante o uso da equação de Van't Hoff (Souza et al., 2012) sendo, em seguida, convertidos em MPa.

Os resultados obtidos foram interpretados por meio de análises de variância e de regressão para as variáveis quantitativas e teste de Tukey para as variáveis qualitativas. O critério para a escolha do modelo foi o maior valor do coeficiente de determinação $\left(\mathrm{R}^{2}\right)$, através do programa estatístico SAEG (2007).

\section{Resultados e Discussão}

Após a suspensão da irrigação por 11 e 16 dias, para os solos de texturas franco-arenosa e franco-argilosa, respectivamente, o ponto de murcha permanente fisiológico do feijoeiro caupi só foi estabelecido nas plantas do tratamento testemunha. Nos demais tratamentos, devido à adaptação da planta à condição de estresse salino, o feijoeiro não apresentou sintomas de murcha irreversível no período considerado de suspensão da irrigação apresentando, portanto, elevados valores de umidade no solo.

Foram observadas respostas lineares e crescentes dos teores de umidade nos solos em função do aumento da salinidade dos solos (Figura 1). No solo de textura franco-arenosa o menor armazenamento de água $\left(0,015 \mathrm{~g} \mathrm{~g}^{-1}\right)$ ocorreu no tratamento testemunha $\left(\mathrm{CE}=2,2 \mathrm{dS} \mathrm{m}^{-1}\right)$ enquanto que o maior armazenamento de água no solo $\left(0,133 \mathrm{~g} \mathrm{~g}^{-1}\right)$ foi verificado no tratamento com a maior salinidade $(\mathrm{CE}=12 \mathrm{dS}$ $\mathrm{m}^{-1}$ ). Comportamento semelhante foi observado no solo de textura franco-argilosa, no qual a maior salinidade $\left(12 \mathrm{dS} \mathrm{m}^{-1}\right)$ proporcionou aumento de $330 \%$ na umidade do solo, quando comparado com o tratamento testemunha $\left(2,4 \mathrm{dS} \mathrm{m}^{-1}\right)$, cujo valor foi de $0,050 \mathrm{~g} \mathrm{~g}^{-1}$.

Esses resultados ocorreram em razão da presença de quantidades consideráveis de sais solúveis na solução do solo, os quais ocasionaram limitações na absorção de água pela planta, tornando mais negativo seu potencial osmótico e, possivelmente, por apresentar menor taxa evapotranspirativa 


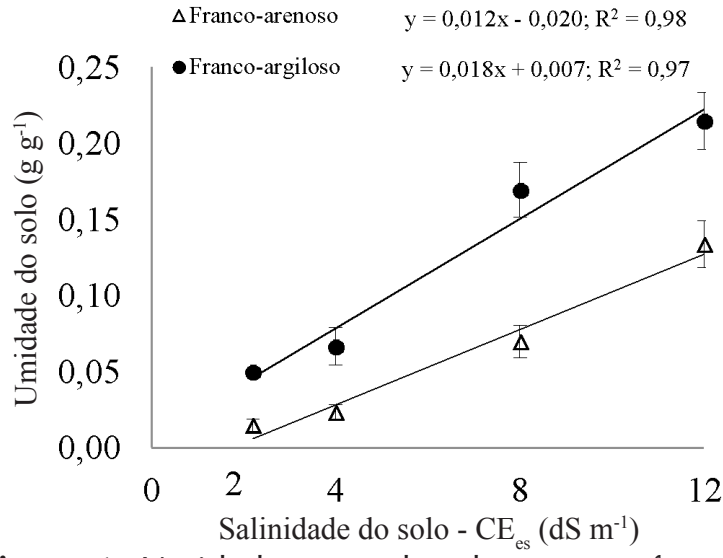

Figura 1. Umidade nos solos de texturas francoarenosa e franco-argilosa, em função da salinidade dos solos, após a suspensão da irrigação por 11 e 16 dias, respectivamente

(Coelho et al., 2013) em consequência da planta possuir um número menor de folhas e menor área foliar. De maneira semelhante, tomateiros cultivados sob condições mais salinas consumiram, em média, $40 \%$ menos água do que plantas controle e também apresentaram redução do crescimento (Reina-Sánchez et al., 2005).

Os valores de ponto de murcha permanente obtidos pelos métodos da câmara de pressão de Richards (Klute, 1986) e fisiológico para os tratamentos testemunhas, usando o feijoeiro caupi como cultura indicadora se acham na Tabela 3 .

Os resultados obtidos pelo método câmara de pressão de Richards superaram o método fisiológico em 33,3 e 18,0\%, para os solos de texturas franco-arenosa e franco-argilosa, respectivamente (Tabela 3). Esses resultados evidenciam que o feijoeiro caupi foi capaz de extrair água a potenciais mais baixos que -1,5 $\mathrm{MPa}$, o que contribuiu para o aumento da água disponível no solo para as plantas em relação ao valor obtido no método do extrator de Richards, passível de significar maior tolerância do feijoeiro caupi à seca em relação a outras espécies. O emprego do método fisiológico para a determinação do ponto de murcha permanente é uma prática mais abrangente, visto que também considerada a capacidade de absorção de água de cada espécie vegetal, especialmente em ambientes salinizados onde, mesmo havendo umidade disponível no solo, a planta tem restringida sua capacidade de absorção de água. Deste ponto de vista a disponibilidade de água no solo depende ainda da taxa de absorção da raiz, a qual é necessária para atender às necessidades de transpiração das plantas (Novák \& Havrila, 2006).

Verifica-se, considerando as texturas dos solos, um armazenamento maior de água no solo franco-argiloso o

Tabela 3. Umidade do solo no ponto de murcha permanente obtido pelos métodos do extrator de Richards e fisiológico

\begin{tabular}{ccc}
\hline \multirow{2}{*}{ Textura do solo } & \multicolumn{2}{c}{ Ponto de murcha permanente $\left(\mathbf{g ~ g}^{-1}\right)$} \\
\cline { 2 - 3 } Franco-arenoso & Extrator Richards & Fisiológico \\
Franco-argiloso & $0,020 \mathrm{a}$ & $0,015 \mathrm{~b}$ \\
\hline
\end{tabular}

Médias seguidas de mesma letra nas linhas, não diferem estatisticamente entre si a 0,05 de probabilidade que possibilitou, ao feijoeiro, suportar cinco dias a mais que o cultivado no solo de textura franco-arenosa para o estabelecimento do murchamento permanente (tratamento testemunha); este evento ocorreu em virtude do maior teor de argila presente no solo franco-argiloso $\left(298 \mathrm{~g} \mathrm{~kg}^{-1}\right)$ em relação ao solo franco-arenoso $\left(98 \mathrm{~g} \mathrm{~kg}^{-1}\right)$.

Não houve efeito significativo dos fatores textura de solo e nível de salinidade do solo sobre o teor de umidade nas folhas do feijoeiro caupi submetido apenas ao estresse salino. Os valores médios da umidade foliar do feijoeiro foram de 91,4 e $90,8 \%$, respectivamente, para as plantas cultivadas em solos de textura franco-arenosa e franco-argilosa (Figura 2A). A manutenção da umidade foliar, verificada nas plantas submetidas ao estresse salino pode ser indicativo de um mecanismo protetor eficiente constituído de ajuste osmótico e redução da transpiração (Meloni et al., 2004). Resultados semelhantes foram obtidos com as cultivares de feijoeiros caupi: TVu, CE 670, Vita 3 e BR 10 Piauí, os quais não alteraram sua turgescência foliar com o aumento da salinidade até 75 $\mathrm{mM}$ de $\mathrm{NaCl}$ (Costa et al., 2003).

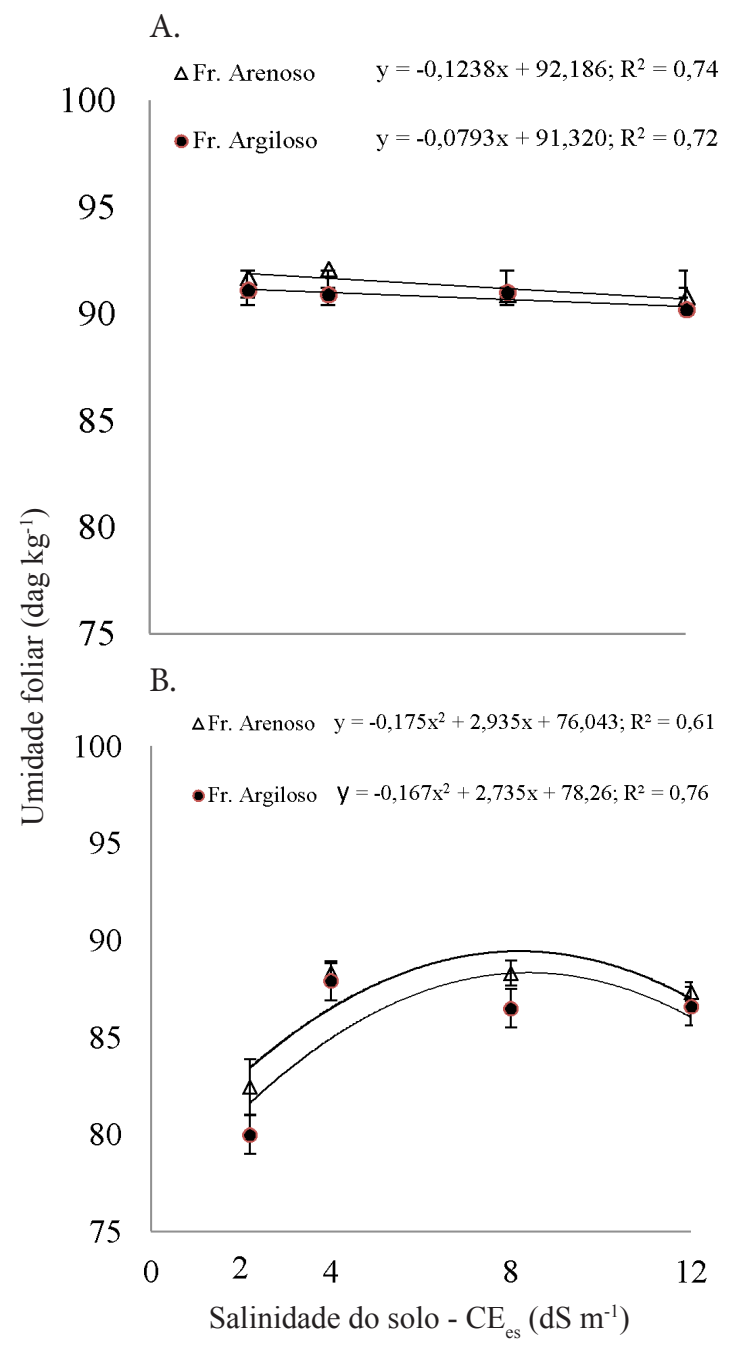

Figura 2. Umidade foliar do feijoeiro caupi em função da salinidade dos solos franco-arenoso e francoargiloso, submetidos a estresse salino (A) e estresse salino seguido de suspensão da irrigação (B) 
Também não houve efeito significativo da interação dos fatores textura de solo e nível de salinidade do solo sobre o teor de umidade foliar do feijoeiro caupi após a suspensão da irrigação por onze e dezesseis dias, para os Neossolos francoarenoso e franco-argiloso, respectivamente. Verificou-se, porém, haver efeito significativo isolado dos fatores textura de solo e nível de salinidade do solo, condições em que se observou, também, um aumento significativo no teor de umidade nas folhas das plantas submetidas ao tratamento $4 \mathrm{dS} \mathrm{m}^{-1}$, comparadas com as testemunhas (Figura 2B). A partir deste tratamento salino o teor de umidade nas folhas das plantas se manteve ligeiramente estável até o mais elevado tratamento salino adotado no experimento $\left(12 \mathrm{dS} \mathrm{m}^{-1}\right)$.

Esses resultados evidenciam maior tolerância do feijoeiro caupi ao déficit hídrico quando o mesmo é submetido simultaneamente a estresse salino e hídrico, pela existência dos mecanismos protetores anteriormente citados.

Quando as plantas foram submetidas apenas ao estresse salino, os resultados mostraram haver resposta linear e decrescente do potencial osmótico foliar, em função da salinidade dos solos (Figura 3A). No Neossolo franco-arenoso o maior potencial osmótico $(-0,648 \mathrm{MPa})$ foi observado no tratamento testemunha $\left(2,2 \mathrm{dS} \mathrm{m}^{-1}\right)$ enquanto que no tratamento com maior salinidade $\left(12 \mathrm{dS} \mathrm{m}^{-1}\right)$ o potencial osmótico foliar do feijoeiro apresentou valor de $-1,012 \mathrm{MPa}$, que corresponde a uma redução de 56,2\%; comportamento semelhante foi observado no Neossolo de textura franco-argilosa. A maior salinidade $\left(12 \mathrm{dS} \mathrm{m}^{-1}\right.$ ) proporcionou redução de $51,2 \%$ no potencial osmótico foliar quando comparado com o tratamento testemunha $\left(2,4 \mathrm{dS} \mathrm{m}^{-1}\right)$ cujo valor foi de $-0,734 \mathrm{MPa}$.

Os valores de potencial osmótico observados neste estudo revelaram que o incremento de sais no solo ocasionou grande redução no status energético da água na planta. Essas reduções representam um ajuste visando manter a turgescência celular da planta, condição necessária para a manutenção do crescimento. Reduções no potencial osmótico foliar em função da presença de sais no solo e concomitante manutenção da turgescência foliar, foram referidas nas culturas de tomate (Maggio et al., 2007) e pinhão-manso (Silva et al., 2009).

Mesmo na condição de estresse salino severo e intensa demanda evapotranspirativa, a cultivar Pele de Moça foi capaz de manter seus processos metabólicos mesmo que em níveis menores, através de mecanismos que evitam a perda de água incluindo o acúmulo de solutos compatíveis nos tecidos foliares, com consequente ajustamento osmótico permitindo a sobrevivência da planta.

O potencial osmótico foliar das plantas submetidas ao estresse salino seguido de suspensão da irrigação (Figura 3B), cultivadas em ambos os solos, apresentou uma tendência de curva parabólica, com leve aumento nos tratamentos submetidos à salinidade equivalente a $4 \mathrm{e} 8 \mathrm{dS} \mathrm{m}^{-1}$, em relação ao tratamento testemunha e posterior declínio no tratamento com $12 \mathrm{dS} \mathrm{m}^{-1}$.

Esses resultados têm respaldo em trabalho desenvolvido por Souza et al. (2011) que também observaram diminuição do potencial hídrico em folhas de feijoeiros caupi com o aumento da salinidade $(200 \mathrm{mM}$ de $\mathrm{NaCl})$ devido à alta acumulação de $\mathrm{Na}^{+}, \mathrm{Cl}^{-}$e $\mathrm{K}^{+}$(Hasegawa et al., 2000).

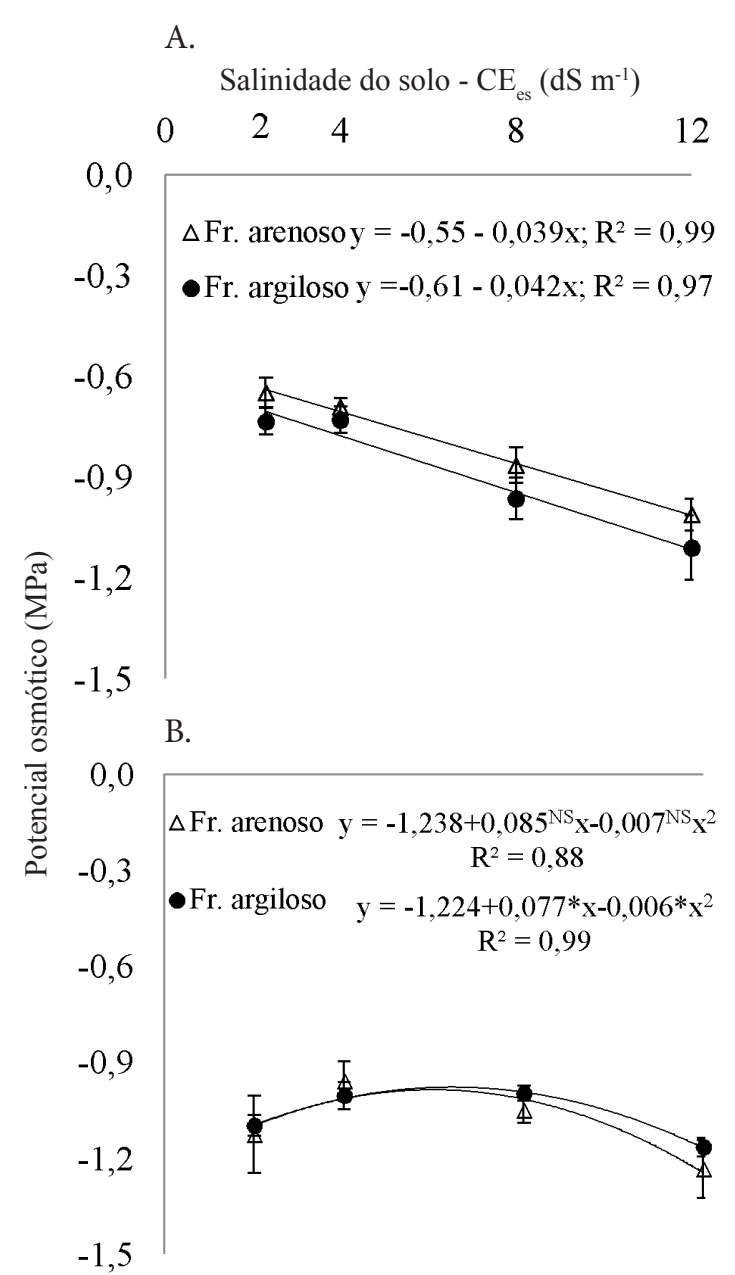

* Significante a nível de 0,05 ; ** Significante a nível de 0,01; NS -resultado não significativo

Figura 3. Potencial osmótico foliar do feijoeiro caupi em função da salinidade dos solos franco-arenoso e franco-argiloso submetidos ao estresse salino (A) e ao estresse salino seguido de suspensão da irrigação (B)

Durante toda a aplicação dos estresses salino e salino + hídrico, as folhas dos feijoeiros submetidos às salinidades do solo equivalentes a 8 e $12 \mathrm{dS} \mathrm{m}^{-1}$, sempre se apresentaram expandidas, indicando ausência de murchamento.

\section{Conclusões}

1. O ponto de murcha permanente do feijoeiro caupi é menor quando determinado pelo método fisiológico do que quando determinado com a câmara de pressão de Richards.

2. O aumento da salinidade do solo até $12 \mathrm{dS}^{-1}$ não influencia a umidade foliar do feijoeiro caupi, independente da textura do solo.

3. O potencial osmótico das folhas do feijoeiro caupi diminui com o aumento da salinidade do solo e pode ser usado como variável importante em ambientes salinizados.

\section{Agradecimentos}

Ao Instituto Agronômico de Pernambuco (IPA) pelo fornecimento das sementes de feijão caupi, cultivar Pele de Moça. 


\section{Literatura Citada}

Alves, W. W. A.; Oliveira, F. de A.; Azevedo, C. A. V. de; Albuquerque, J. H. de. Métodos de determinação e níveis de água disponível no solo: efeito sobre a cultura do algodoeiro herbáceo. Revista Caatinga, v.23, p.91-94, 2010.

Ayers, R. S.; Westcot, D. W. A qualidade de água na agricultura. 2.ed. Campina Grande: UFPB, 1999. 153p. FAO. Irrigação e Drenagem.

Ben-Gal, A.; H, Yermiyahu, U.; Shani, U. Is osmotic potential a more appropriate property than electrical conductivity for evaluating whole-plant response to salinity? Environmental and Experimental Botany, v.65, p.232-237, 2009.

Bezerra Neto, E.; Barreto, L. P. Análises químicas e bioquímicas em plantas. Recife:UFRPE, 2011. 267p.

Briggs, L. J.; Shantz, H. L.The wilting coefficient for different plants and its indirect determination. Washington: Department of Agriculture, Bureau of Plant Industries.U. S. Gov. Printing Office, 1912. 83p. Bulletin no 30.

Coelho, J. B. M.; Barros, M. F. C.; Bezerra Neto, E.; Correa, M. M. Comportamento hídrico e crescimento do feijão vigna cultivado em solos salinizados. Revista Brasileira de Engenharia Agrícola e Ambiental, v.17, p.379-385, 2013.

Costa, P. H. A.; Silva, J. V.; Bezerra, M. A.; Enéas Filho, J.; Prisco, J. T.; Gomes Filho, E. Crescimento e níveis de solutos orgânicos e inorgânicos em cultivares de Vignaunguiculata submetidos à salinidade. Revista Brasileira de Botânica, v.26, p.289-297, 2003.

EMBRAPA - Empresa Brasileira de Pesquisa Agropecuária. Manual de métodos de análises de solo. 2.ed. Rio de Janeiro: Ministério da Agricultura e do Abastecimento, 1997. 212p.

Haseagawa, P. M.; Bressan, R. A.; Zhu, J. K. Bohnert, H. J. Plant cellular and molecular responses to high salinity. Annual Review of Plant Physiology and Plant Molecular Biology, v.51, p.463-499, 2000.

Klein, V. A.; Reichert, J. M.; Reinert, D. J. Água disponível em um latossolo vermelho argiloso e murcha fisiológica de culturas. Revista Brasileira de Engenharia Agrícola e Ambiental, v.10, p.646-650, 2006.

Klute, A. Waterretention: laboratory methods. In: Black, C. A. (Ed.). Methods of soil analysis. I. Physical and mineralogical methods. Madison: Soil Society of America, 1986, p.635-662.
Lima, C. J. G. S.; Oliveira, F. A.; Medeiros J. F. de; Oliveira M. K. T.; Almeida Júnior, A. B. Resposta do feijão caupi a salinidade da água de irrigação. Revista Verde de Agroecologia e Desenvolvimento Sustentável, v.2, p.79-86, 2007.

Maggio, A.; Raimondi, G.; Martino, A.; De Pascale, S. Salt stress response in tomato beyond the salinity tolerance threshold. Environmental and Experimental Botany, v.59, p.276-282, 2007.

Meloni, D. A.; Gulotta, M. R.; Martínez, C. A.; Oliva, M. A.The effects of salt stress on growth, nitrate reduction and proline and glycine betaine accumulation in Prosopisalba. Revista Brasileira de Fisiologia Vegetal, v.16, p.39-46, 2004.

Munns, R. Comparative physiology of salt and water stress. Plant, Cell and Environment, v.25, p.239-250, 2002.

Novák, V.; Havrila, J. Method to estimate the critical soil water content of limited availability for plants. Biologia, v.61, p.289-293, 2006.

Patel, P. R.; Kajal, S. S.; Patel, V. R.; Patel, V. J.; Khristi, S. M. Impact of saline water stress on nutrient uptake and growth of cowpea. Brazilian Journal Plant Physiology.v.22, p.43-48, 2010.

Reina-Sánchez, A.; Romero-Aranda, R.; Cuartero, J. Plant water uptake and water use efficiency of greenhouse tomato cultivars irrigated with saline water. Agricultural Water Management, v.78, p.54-66, 2005.

Richards, L. A. Diagnosis and improvement of saline and alkali soils. Washington: US Department of Agriculture, 1954. 160p. USDA Agricultural Handbook, 60.

SAEG. Sistema para análises estatísticas, Versão 9.1. Viçosa: Fundação Arthur Bernardes; Universidade Federal de Viçosa, 2007.

Silva, E. N. da; Silveira, J. A. G.; Rodrigues, C. R. F.; Lima, C. S. de; Viégas, R. A. Contribuição de solutos orgânicos e inorgânicos no ajustamento osmótico de pinhão-manso submetido à salinidade. Pesquisa Agropecuária Brasileira, v.44, p.437-445, 2009.

Souza, E. R. de; Freire, M. B. G. dos S.; Cunha, K. P. V. da; Nascimento, C. W. A. do; Ruiz, H. A.; Lins, C. M. T. Biomass, anatomical change sand osmotic potential in Atriplex numulária $\mathrm{L}$ indl. cultivated in sodic saline soil under water stress. Environmental and Experimental Botany, v.82, p.2027, 2012.

Souza, R. P.; Machado, E. C.; Silveira, J. A. G.; Ribeiro, R. V. Fotossíntese e acúmulo de solutos em feijoeiro caupi submetido à salinidade. Pesquisa Agropecuária Brasileira, v.46, p.587-592, 2011. 